\title{
Development of Novel Wheat-Rye Chromosome 4R Translocations and Assignment of Their Powdery Mildew Resistance
}

\author{
Pengtao Ma, ${ }^{1}$ Guohao Han, ${ }^{1}$ Qi Zheng, ${ }^{2}$ Shiyu Liu, ${ }^{1}$ Fangpu Han, ${ }^{2}$ Jing Wang, ${ }^{1}$ Qiaoling Luo, ${ }^{2}$ and Diaoguo An ${ }^{1,3, \dagger}$ \\ ${ }^{1}$ Center for Agricultural Resources Research, Institute of Genetics and Developmental Biology, Chinese Academy of Sciences, \\ Shijiazhuang 050021, China \\ ${ }^{2}$ State Key Laboratory of Plant Cell and Chromosome Engineering, Institute of Genetics and Developmental Biology, Chinese \\ Academy of Sciences, Beijing 100101, China \\ ${ }^{3}$ Innovative Academy of Seed Design, Chinese Academy of Sciences, Beijing, China
}

\begin{abstract}
Rye (Secale cereale L.) is an important gene donor for wheat improvement because of its many valuable traits, especially disease resistance. Development of novel wheat-rye translocations with disease resistance can contribute to transferring resistance into common wheat. In a previous study, a wheat-rye T4BL-4RL and T7AS·4RS translocation line (WR41-1) was developed by distant hybridization, and it was speculated that its resistance to powdery mildew, caused by Blumeria graminis $\mathrm{f}$. sp. tritici (Bgt), was derived from rye based on pedigree analysis. To make accurate use of chromosome $4 \mathrm{R}$ in wheat improvement, a set of new 4R translocations involving different arm translocations (e.g., 4RS monosomic, 4RL monosomic, 4RL disomic, 4RS monosomic plus 4RL monosomic, 4RS monosomic plus 4RL disomic, and 4RS disomic

hybridization and expressed sequence tag simple sequence repeat marker analysis. To confirm the source of powdery mildew resistance, the translocation plants were tested against Bgt isolate E09. The results indicated that all translocations with 4RL were resistant at all tested growth stages, whereas those with only $4 \mathrm{RS}$ translocation or no alien translocation were susceptible. This further indicated that the powdery mildew resistance of WR41-1 was derived from the alien chromosome arm 4RL. To effectively use 4RL resistance in wheat improvement, two competitive allele-specific PCR markers specific for chromosome arm 4RL were developed to detect the alien chromosome in the wheat genome. These new translocation lines with diagnostic markers can efficiently serve as important bridges for wheat improvement.
\end{abstract} plus 4RL disomic translocations) was developed from crosses with common wheat. Those translocations were characterized by genomic in situ
Keywords: cereals and grains, disease management, field crops, fungi
Wheat powdery mildew, caused by Blumeria graminis (DC.) Speer f. sp. tritici emend. É. J. Marchal (Bgt), is a devastating disease that threatens wheat yield and quality (Morgounov et al. 2012). Host resistance is considered to be the most effective and environmentfriendly means to control this disease (Selter et al. 2013). A total of 88 formally designated powdery mildew resistance $(\mathrm{Pm})$ genes/ alleles at 65 loci (Pml to Pm65) and 20 temporarily designated $\mathrm{Pm}$ genes have been identified to date; these genes are distributed on most of the chromosomes in wheat and several chromosomes of its relatives ( $\mathrm{Li}$ et al. 2019; McIntosh et al. 2017). However, with the coevolution between pathogen virulence and host resistance, most of the resistance genes that have been deployed in large-scale commercial production have often been successively defeated by new virulent isolates in some areas, including Pmla, Pmlc, Pm2, Pm3a, Pm3b, Pm3c, Pm3e, Pm3f, Pm3g, Pm4a, Pm4b, Pm5a, Pm5b, Pm6, Pm7, Pm8, Pm9, Pm17, Pm25, Pm34, and Pm35 (Cowger et al. 2018; Ma et al. 2015; Parks et al. 2008). Therefore, it is a

Current address of P. Ma: School of Life Sciences, Yantai University, Yantai, Shandong 264005, China.

${ }^{\dagger}$ Corresponding author: D. An; dgan@sjziam.ac.cn

P. Ma and G. Han contributed equally to this work.

Funding: This research was supported by the National Key Research and Development Program of China (grant 2016YFD0102002), the National Natural Science Foundation of China (grant 31771793), and the STS Project of the Chinese Academy of Sciences (grant KFJ-STS-ZDTP-024).

The author(s) declare no conflict of interest.

Accepted for publication 8 July 2019.

(C) 2020 The American Phytopathological Society constant challenge to exploit new resistance resources for wheat improvement.

Rye (Secale cereale L., $2 \mathrm{n}=2 \mathrm{x}=14$, RR) is a close relative of common wheat and has proven to be an important gene donor in wheat improvement for resistance to multiple diseases such as powdery mildew (An et al. 2019). To date, five formally designated $P m$ genes derived from rye have been identified and transferred into the wheat genome. They include $P m 7, P m 8, P m 17, P m 20$, and Pm56 from rye chromosome arms $2 \mathrm{RL}, 1 \mathrm{RS}, 1 \mathrm{RS}, 6 \mathrm{RL}$, and $6 \mathrm{RS}$, respectively (Friebe et al. 1994, 1996; Hao et al. 2018; Heun et al. 1990; Hsam and Zeller 1997). Of these, $P m 8$ is one of the most effective and widely used $P m$ genes in the last century and has made a great contribution to control wheat powdery mildew (Huang and Röder 2004; Zeller and Hsam 1996). Apart from these formally designated $\mathrm{Pm}$ genes, some wheat-rye progenies in the form of chromosome translocation, addition, or substitution lines also expressed powdery mildew resistance and were considered to be derived from rye. They include the 5DS-4RS-4RL and 4RS-5DS-5DL translocation lines of common wheat Mianyang 11 and winter rye cultivar Kustro (Fu et al. 2014); the $2 \mathrm{R}$ addition line of Chinese wheat landrace Huixianhong and rye cultivar Jingzhouheimai (Zhuang et al. 2011); the introgression line of rye cultivar Jingzhouheimai and common wheat (Yu et al. 2012); and the T2BL·1RS translocation line, 2R (2D) substitution line, and $4 \mathrm{R}$ and $6 \mathrm{R}$ addition lines of common wheat cultivar Xiaoyan 6 and rye cultivar German White (An et al. 2006, 2015, 2019; Wang et al. 2009).

Compared with chromosome addition and substitution lines, translocation lines are preferred by wheat breeders because of the smaller amount of alien genetic material, less linkage drag, and their regular meiotic behavior (Falke et al. 2009; Qi et al. 2016). Several methods have been used to develop translocation lines, such as conventional hybridization (Tang et al. 2014; Zhang et al. 2005), ${ }^{60} \mathrm{Co} \gamma$ radiation (Chen et al. 2013; Zhang et al. 2016), phlb-induced homeologous recombination (Danilova et al. 2017; Liu et al. 2017; Rahmatov et al. 2016), and gametocidal chromosomes originating from Aegilops species (Chen et al. 2005; Endo 2007). Genomic in situ hybridization 
(GISH) and fluorescence in situ hybridization (FISH), especially multicolor FISH, are advanced methods for identifying and analyzing the alien chromatin introgressed into the wheat genome (An et al. 2006, 2013, 2015, 2019). Alien chromosome-specific markers are also powerful for detecting alien chromatins in the wheat genome (Hechanova et al. 2018; Zhang et al. 2019). With the rapid development of high-throughput single nucleotide polymorphism (SNP) genotyping, kompetitive allele-specific PCR (KASP) markers have been developed into efficient techniques for detecting and mapping target genes and chromosome segments (Dhakal et al. 2018). Combining GISH/FISH with efficient alien chromosome-specific markers has been widely used to accelerate the process and improve outcomes of wheat-alien breeding programs (Edet et al. 2018; Hechanova et al. 2018). Zhang et al. (2018) identified and transferred Pm62 from Dasypyrum villosum into common wheat in the form of the Robertsonian translocation T2BS·2VL\#5. Danilova et al. (2018) developed a complete set of wheat-barley group-7 Robertsonian translocation chromosomes that conferred increased $\beta$-glucan content. Ren et al. (2018) identified a novel source of 1RS from Baili rye that conferred high resistance to stripe rust (Puccinia striiformis f. sp. tritici) and powdery mildew and improved yield traits in common wheat.

In a previous study, a wheat-rye T4BL·4RL and T7AS·4RS translocation line (WR41-1) with novel powdery mildew resistance was produced by distant hybridization and chromosome engineering between wheat cultivar Xiaoyan 6 and rye cultivar German White (An et al. 2013). To develop novel translocations and identify the powdery mildew resistance loci of WR41-1, the objectives of this study were to (i) develop a set of wheat-rye $4 \mathrm{R}$ translocations involving different arm translocations, (ii) confirm the identification of the alien chromosome arm(s) by GISH and molecular markers specific for the chromosome 4R arms, (iii) determine the location of the powdery mildew resistance in WR41-1 and assign it to a specific chromosome arm, and (iv) develop KASP markers specific for chromosome arm 4RL for its efficient detection in a wheat background and application in resistance breeding.

\section{Materials and Methods}

Plant materials. WR41-1 is a wheat-rye T4BL-4RL and T7AS-4RS translocation line (An et al. 2013). In this study, WR41-1 was used as a bridge parent to produce different chromosome 4R translocations. Wheat cultivar Shixin 633, which is susceptible to powdery mildew, was used as the receptor parent to produce new translocations of chromosome 4R through conventional hybridization. Wheat cultivars Mingxian 169 and Huixianhong were used as the susceptible controls for testing powdery mildew resistance at both the seedling and adult stages. Total genomic DNA was extracted from wheat cultivar Chinese Spring (CS; ABD genomes) and used as the blocking DNA in GISH detection. All of the seedlings used for DNA extraction were grown in an illumination incubator set at 18 to $20^{\circ} \mathrm{C}$, with $18 \mathrm{~h}$ of light and $6 \mathrm{~h}$ of darkness and $75 \% \mathrm{RH}$. Two sets of wheat-rye addition lines (Holdfast-King II and CS-Imperial), a set of wheat-rye ditelosomic addition lines of Holdfast-King II, and a 4RS ditelosomic addition line and a 4RL ditelosomic addition line of CS-Imperial were used for the development and validation of rye chromosome-specific KASP markers. The wheat parent of WR41-1 (Xiaoyan 6), rye cultivar King II, and wheat cultivar Holdfast were used as controls in confirming 4RL-specific markers in this study.

Development of $4 R$ translocation lines containing different types of arm translocations. WR41-1 was crossed as the female parent with susceptible cultivar Shixin 633, which has no rye chromatin based on GISH. The $\mathrm{F}_{1}$ hybrid seeds were planted in the field to harvest $\mathrm{F}_{2}$ seeds for GISH and molecular marker detection.

GISH analysis. Seeds were germinated in Petri dishes on moistened filter paper. Root tips were collected from actively growing seedlings. Procedures for pretreatment, mitotic chromosomes spreads, and observation of the root tip cell were as described by Han et al. (2006). Total genomic DNA of rye cultivar German White was extracted (Sharp et al. 1988) and labeled with fluorescein-12-dUTP by the nick translation method (Guo et al. 2015). Detection and visualization of the prepared samples was carried out as previously described by Han et al.
(2009). A DVC charge-coupled device digital camera was used to capture images of the cells with good hybridization signals. Image-Pro Plus 4.0 software was used to merge the images captured for each color channel.

Molecular marker analysis. Two expressed sequence tag simple sequence repeat (EST-SSR) markers KSUM62 and MAG1424 specific for chromosome arms 4RS and 4RL, respectively (An et al. 2013), were used to detect the rye chromosome $\operatorname{arm}(\mathrm{s})$ in the $F_{2}$ plants of Shixin 633 and WR41-1 using GISH. After the $F_{2}$ translocations were selected, they were transplanted to the field to harvest $\mathrm{F}_{3}$ seeds. The $\mathrm{F}_{3}$ plants were also screened with markers KSUM62 and MAG1424 to confirm their translocations and genetic stability. The genomic DNA was extracted from each of these seedlings using the method of He et al. (2017). The PCR profile was set as follows: one cycle at $94^{\circ} \mathrm{C}$ for $5 \mathrm{~min}$, followed by 38 cycles at $94^{\circ} \mathrm{C}$ for $1 \mathrm{~min}$, $62^{\circ} \mathrm{C}$ (KSUM62) or $52^{\circ} \mathrm{C}$ (MAG1424) for $1 \mathrm{~min}$, and $72^{\circ} \mathrm{C}$ for 40 $\mathrm{s}$, with a final extension at $72^{\circ} \mathrm{C}$ for $5 \mathrm{~min}$ (Xu et al. 2012). PCR products were separated in $8 \%$ nondenaturing polyacrylamide gels with a 19:1, 29:1, or 39:1 ratio of acrylamide/bis-acrylamide and then visualized by silver staining and photographed (Ma et al. 2018b).

Assessment of powdery mildew resistance. After GISH and molecular marker identification, the seedlings of Shixin 633, WR41-1, and their $\mathrm{F}_{2}$ plants were tested for their reactions to Bgt isolate E09, which is common in northern China with a special virulence spectrum (An et al. 2013). Three seedlings per cell were planted in rectangular trays with 72 cells $(3 \mathrm{~cm} \times 3 \mathrm{~cm})$ in the greenhouse. The susceptible checks Mingxian 169 and Huixianhong were randomly planted in the trays. At the one- to two-leaf stage, separate artificial inoculation with fresh spores using the dusting method was carried out in a manually controlled climatic box with a daily cycle of $14 \mathrm{~h}$ of light at $22^{\circ} \mathrm{C}$ and $10 \mathrm{~h}$ of darkness set at $18^{\circ} \mathrm{C}$ (An et al. 2013). When pustules were fully developed on the first leaf of susceptible control Mingxian 169, the infection type (IT) of each plant was scored based on a 0 to 4 scale, in which plants with IT scores of 0,$0 ;, 1$ and 2 were considered as immune, necrotic, highly resistant, and moderately resistant, respectively, and plants with IT scores of 3 and 4 were considered as moderately and highly susceptible, respectively (Si et al. 1992).

After the seedlings were labeled, Shixin 633, WR41-1, and their $F_{2}$ plants were transplanted to the field. The susceptible checks Mingxian 169 and Huixianhong were planted around the $\mathrm{F}_{2}$ population of Shixin $633 \times$ WR41-1. At the boot and milk growth stages (Zadoks et al. 1974), they were tested for their reactions to a mixture of Bgt isolates collected in Shijiazhuang, China. The procedures for the powdery mildew test at the adult plant stage were performed as described by Sheng and Duan (1991) at the Chinese Academy of Sciences Luancheng Agro-Ecological Experimental Station in Shijiazhuang, China. The powdery mildew reactions were assessed using a 0 to 9 scale, where 0,1 to 2 , and 3 to 4 were considered as immune, highly resistant, and moderately resistant, respectively, and 5 to 6 and 7 to 9 were considered as moderately and highly susceptible, respectively (Sheng and Duan 1991). Wheat cultivars Mingxian 169 and Huixianhong were used as the susceptible controls.

Development and validation of KASP markers. PCR-based primers were designed using Primer 3 software (http://www.primer3plus.com/primer3web/) according to the rye-specific sequences obtained from specific-locus amplified fragment sequencing (SLAF-seq) and sequence alignment, following the procedure of Liu et al. (2018). The wheat cultivar Holdfast, rye cultivar King II, and the complete set of wheat-rye disomic addition lines and ditelosomic addition lines of Holdfast-King II were used to locate markers on the rye chromosome arms. The PCR amplification procedure was performed using the same method as previously mentioned, except the optimal melting temperature was set at $58^{\circ} \mathrm{C}$.

The PCR-based markers specific for 4RL were used to develop KASP markers. To find the appropriate sequences with a size between 40 and $120 \mathrm{bp}$ and only a single unique SNP, the original SLAF sequences were compared with the CS reference sequences in the International Wheat Genome Sequencing Consortium (IWGSC) Ref Seq version 1.0 database (https://wheat-urgi.versailles.inra.fr/Seq-Repository/News). KASP 
markers were designed based on the obtained sequences using Primer 3 software. Subsequently, these markers were validated using the complete set of wheat-rye disomic addition lines, the 4RS ditelosomic addition line, and the 4RL ditelosomic addition line of CS-Imperial. In addition, wheat cultivars, rye cultivars, and chromosome $4 \mathrm{R}$ translocations that had been characterized by GISH were also used to confirm the specificity and stability of the KASP markers developed in this study.

Amplification with KASP primers was performed in a Bio-Rad CFX real-time PCR system with a final volume of $8 \mu$ l containing $2.4 \mu \mathrm{l}$ of genomic DNA (50 ng), $4.5 \mu \mathrm{l}$ of $2 \times$ KASP Master Mix, and $0.14 \mu \mathrm{l}$ of primer mix. The amplification procedure was set as follows: $94^{\circ} \mathrm{C}$ for $15 \mathrm{~min}$, followed by 10 touchdown cycles of $94^{\circ} \mathrm{C}$ for $20 \mathrm{~s}$ and 64 to $58^{\circ} \mathrm{C}$ (decreasing $0.6^{\circ} \mathrm{C}$ per cycle) and $38 \mathrm{cy}-$ cles of regular amplification $\left(94^{\circ} \mathrm{C}\right.$ for $20 \mathrm{~s}, 58^{\circ} \mathrm{C}$ for $\left.60 \mathrm{~s}\right)$. The final fluorescence was detected at $20^{\circ} \mathrm{C}$ using Bio-Rad CFX Manager 3.1 software.

\section{Results}

GISH analysis of the chromosome $4 \mathrm{R}$ translocations. GISH analysis using the genomic DNA of German White as a probe was conducted to detect chromosome $4 \mathrm{R}$ arm(s) in the crossed population. Among the $\mathrm{F}_{2}$ plants of Shixin $633 \times \mathrm{WR} 41-1$, three had a single short chromosome arm that displayed bright-green hybridization signals, showing that the DNA in those chromosome arms hybridized with the labeled probes from rye (Fig. 1A). The breakpoint of the translocation in each plant was clear and appeared to be in the centromeric region forming one wheat-rye Robertsonian translocation (Fig. 1A). This result demonstrated that these three plants were 4RS monosomic translocations. Using the same method of analysis, 12 4RL monosomic, three 4RL disomic, three 4RL monosomic plus 4RS monosomic, six 4RL disomic plus 4RS monosomic, and three 4RL disomic plus $4 \mathrm{RS}$ disomic translocations were also obtained from the $\mathrm{F}_{2}$ population (Fig. 1B to F; Table 1).

Molecular marker analysis of the chromosome $4 R$ translocations. To confirm the rye chromosome composition identified by GISH analysis, two EST-SSR markers KSUM62 and MAG1424 specific for the 4RS and 4RL arms of the rye chromosome, respectively (An et al. 2013), were used to detect the chromosome 4R arm(s) in crossed progenies. The results demonstrated that all $4 \mathrm{RS}$ monosomic translocations amplified a 160-bp band specific for chromosome arm 4RS using marker KSUM62, but they did not amplify the 235-bp band specific for chromosome arm 4RL using marker MAG1424 (Fig. 2), indicating that those materials only had the chromosome arm 4RS. Meanwhile, a DNA fragment of about 235 bp was amplified by marker MAG1424 in all 4RL monosomic and disomic translocations, but the 160-bp band specific for chromosome arm 4RS was not amplified in those materials by marker KSUM62 (Fig. 2). This indicated that those materials only had chromosome arm 4RL. Translocations with both chromosome arms 4RS and 4RL had both 160and 235-bp bands amplified by markers KSUM62 and MAG1424, respectively (Fig. 2). Therefore, both chromosome arms $4 \mathrm{RS}$ and 4RL were confirmed in those materials. Based on these results, the marker detection was consistent with that of the GISH analysis; therefore, the alien chromosome compositions of these translocation materials were confirmed by both GISH analysis and marker detection.

Powdery mildew reactions of the chromosome $4 R$ translocations. At the seedling stage, when inoculated with Bgt isolate E09, the WR41-1 seedlings were resistant with IT 0 to 1 and the Shixin 633 seedlings were susceptible with IT 4 . All of the chromosome 4R translocations with only $4 \mathrm{RS}$ translocation, as $4 \mathrm{RS}$ monosomic translocations, were highly susceptible with IT 4 . Those carrying the 4RL translocation, including 4RL monosomic, 4RL disomic, 4RL and 4RS monosomic, 4RL disomic plus the 4RS monosomic, and 4RL disomic plus the $4 \mathrm{RS}$ disomic translocations, were all resistant to isolate E09 with IT 0 to 1 (Table 1). Meanwhile, the plants without any translocations were susceptible to isolate E09 (Table 1). The results demonstrated that the powdery mildew resistance in WR41-1 was derived from rye and assigned to the long arm of the chromosome 4R.
To assess the powdery mildew resistance of the translocations of WR41-1 at different growth stages, line WR41-1, cultivar Shixin 633 , and these $4 \mathrm{R}$ translocations were transplanted to the field and tested for their reactions to a mixture of $B g t$ isolates prevalent in northern China. At the boot growth stage, WR41-1 was resistant with IT 0 to 2 and Shixin 633 was susceptible with IT 7 to 9 . All lines carrying only the $4 \mathrm{RS}$ translocation or with no translocations were highly susceptible with IT 7 to 9 , whereas those with 4RL translocation(s) were resistant to the mixture of $B g t$ isolates with IT 0 to 2 (Table 1). These results were consistent with the powdery mildew reactions at the seedling stage. At the milk growth stage, the powdery mildew reaction pattern was also the same as the results at both seedling and boot stages. Therefore, the $P m$ gene(s) located on chromosome arm $4 \mathrm{RL}$ conferred resistance against powdery mildew throughout the whole growth period.

Inheritance of the chromosome $4 R$ translocations in selfpollinated progenies. To investigate the transfer of the translocated chromosome arm(s) to the next generation and to obtain stable translocations, self-pollinated progenies of several selected chromosome $4 \mathrm{R}$ translocations were surveyed using markers specific for chromosome arms 4RS and 4RL (Fig. 3). The results demonstrated that 16 and eight plants amplified 4RS- or 4RL-specific patterns from the 40 and 155 tested self-pollinated progenies of 4RS monosomic translocation and 4RL monosomic translocations, respectively (Table 2). For the self-pollinated progenies of the 4RL monosomic plus 4RS monosomic translocations, one 4RS translocation, one 4RL translocation, and two translocations with both chromosome arms 4RL and $4 \mathrm{RS}$ were obtained from the 26 plants tested (Table 2). When tested against $B g t$ isolate E09 at the seedling stage and a mixture of $B g t$ isolates at adult stage, all plants with the 4RL translocation(s) were resistant, whereas those with only the 4RS translocation were susceptible, consistent with their phenotypic reaction in the previous generation (Tables 1 and 2). This evaluation of the different generations confirmed that the powdery mildew resistance loci in WR41-1 were located on the chromosome arm 4RL of rye and were expressed in different generations. However, those translocation materials were not genetically stable homozygotes and therefore needed to be selfpollinated further to obtain genetically stable translocation lines.

Development and validation of the codominant KASP markers specific for 4RL. The primers that amplified the specific band in King II, the wheat-rye 4R disomic addition line, and the 4RL ditelosomic addition line but not in other lines from the complete set of wheat-rye addition lines of Holdfast-King II and Holdfast were regarded as 4RL-specific markers. To determine the expected sequences for KASP marker design, two original SLAF sequences of two randomly selected PCR-based markers specific for 4RL were compared with the CS reference sequences in IWGSC Ref Seq version 1.0. Consequently, two codominant KASP markers specific to 4RL (SWK4RL1 and SWK4RL2) were developed (Table 3) and were validated using the complete set of wheat-rye disomic addition lines, the 4RS ditelosomic addition line, and the 4RL ditelosomic addition line of CS-Imperial. Both SWK4RL1 and SWK4RL2 were shown to clearly distinguish three genotypes: orange rotundity shapes indicated the homozygous 4RL special SNP (Allele1/ Allele1) representing rye, blue square shapes indicated the homozygous wheat special SNP (Allele2/Allele2) representing wheat and wheat-rye introgression lines without the chromosome arm 4RL, and green triangle shapes indicated the presence of both Allele1 and Allele2 representing wheat-rye 4RL introgression (Fig. 4).

\section{Discussion}

WR41-1 is a wheat-rye T4BL·4RL and T7AS·4RS translocation line that was produced from a cross of wheat cultivar Xiaoyan 6 and rye cultivar German White. A previous study demonstrated that WR41-1 had novel powdery mildew resistance presumed from rye (An et al. 2013). However, this speculation on the origin of the powdery mildew resistance was only based on pedigree analysis. Through the use of a set of 4R translocations with different translocated arms that were developed in this study, their powdery mildew reactions were determined and the resistance locus was physically 
assigned. When tested against Bgt isolates at three different growth stages, the translocations with only $4 \mathrm{RS}$ or no translocations were all powdery mildew susceptible, but those with the 4RL translocation were all resistant. Therefore, the powdery mildew resistance of WR41-1 was derived from the rye chromosome and assigned to chromosome arm 4RL. Several other wheat-rye 4R lines have also been developed, including the CS-Imperial, CS-King II, Holdfast-King II, and Kharkov-Dakold disomic addition lines (Zhong et al. 2002); 4R monosomic and 4RL monotelosomic or ditelosomic addition lines and T5DS-4RS·4RL and T4RS-5DS·5DL translocation lines of the common wheat cultivar Mianyang 11 and rye cultivar Kustro ( $\mathrm{Fu}$ et al. 2014); and 4R disomic addition line WR35 of wheat cultivar Xiaoyan 6 and rye cultivar German White (An et al. 2019). Some of these wheat-rye $4 \mathrm{R}$ lines also have powdery mildew resistance, such as 4RL translocation lines of wheat cultivar Mianyang 11 and rye cultivar Kustro and the 4R disomic addition line WR35 of
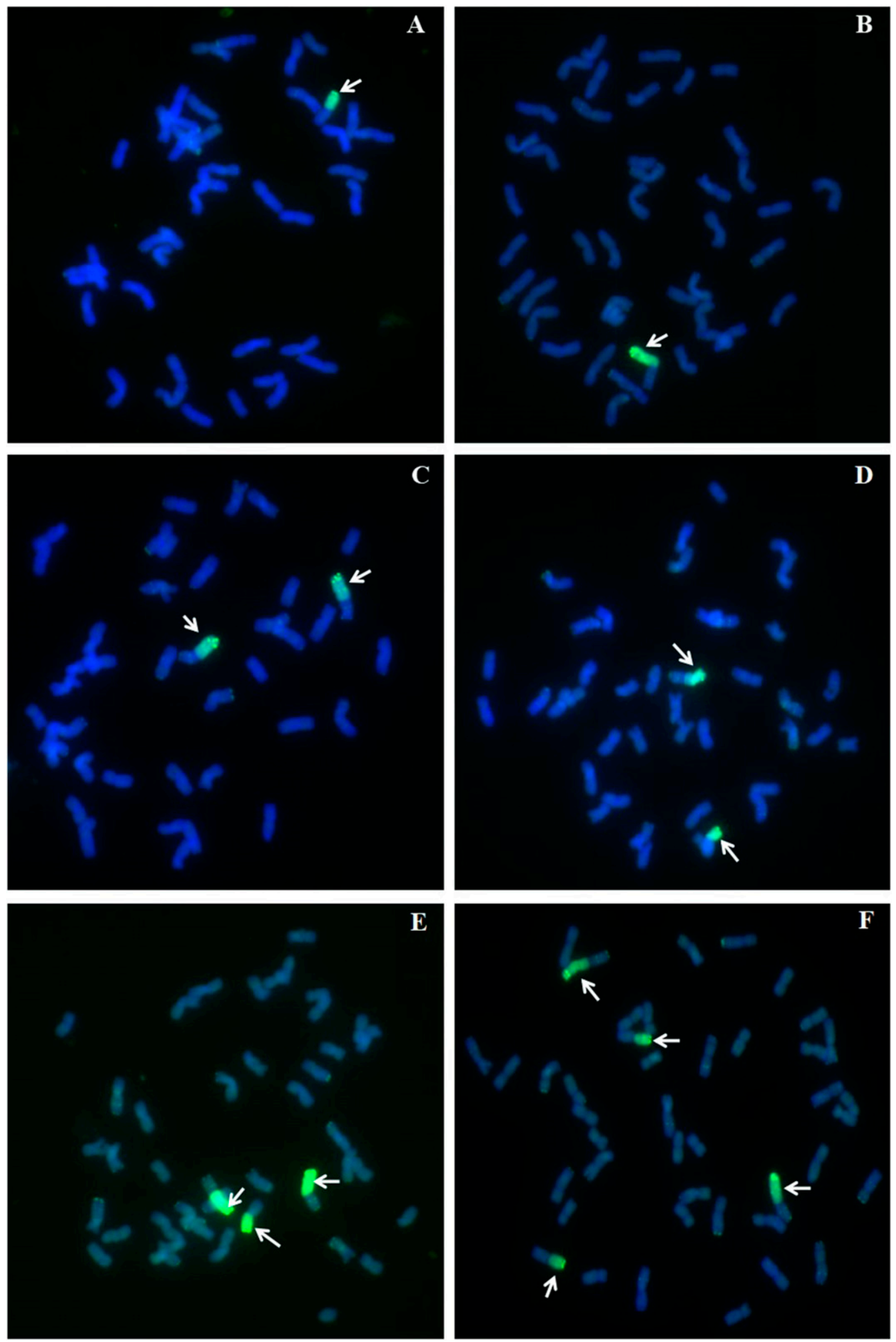

Fig. 1. Genomic in situ hybridization identification of chromosome 4R translocations by the cross of Shixin $633 \times$ WR41-1. A, 4RS monosomic translocation. B, 4RL monosomic translocation. C, 4RL disomic translocation. D, 4RS monosomic plus 4RL monosomic translocation. E, 4RS monosomic plus $4 R L$ disomic translocation. F, 4RS disomic plus 4RS disomic translocation. 
Xiaoyan 6 and German White (An et al. 2019; Fu et al. 2014). In addition, chromosome arm 4RL from the hexaploid triticale cultivar Soreneo also confers powdery mildew resistance (Li et al. 2019). However, as a cross-pollinated crop, rye contains significant genetic heterogeneity within and among cultivars (Chebotar et al. 2003; Chikmawati et al. 2012; Rogowsky et al. 1992; Targońska et al. 2016). The powdery mildew resistance in WR35 also has proven to be different from that of WR41-1 (An et al. 2019). Therefore, the powdery mildew resistance derived from chromosome arm 4RL of rye cultivar German White in this study may different from that of Kustro and Soreneo and could enrich the genetic resources for wheat resistance to powdery mildew.

To enrich the genetic variation of the $4 R$ translocation line, five novel types of translocations, including those only containing 4RS or $4 \mathrm{RL}$ translocations, were developed in this study. They will be very useful for further studies of chromosome arms 4RL or 4RS.
Meanwhile, transmission of the chromosome $4 \mathrm{R}$ arms to the next generation was investigated. Although some progenies lost the alien chromosome arms because of the genetic instability of the translocations, a series of $4 \mathrm{RS}$ or 4RL translocation materials were obtained in the next generation. To obtain stably inherited 4RS or 4RL translocation lines, the selected 4RS or 4RL translocation(s) were planted in the field and were further self-pollinated, from which stably inherited $4 \mathrm{RS}$ or $4 \mathrm{RL}$ disomic translocation lines were selected, which can be used in wheat breeding.

Several other wheat-rye $4 \mathrm{R}$ lines have also been documented, but few have been used in wheat improvement because of poor agronomic performance and their vulnerability to diseases (Martinez et al. 1994; Zeller and Koller 1981). Whether a wheat-alien hybrid can be utilized effectively in wheat breeding depends to some extent on its wheat genetic background. In this study, we used WR41-1 that has a genetic background derived from widely grown

Table 1. Types of chromosome $4 \mathrm{R}$ translocation derived from the $\mathrm{F}_{2}$ plants of wheat-rye T4BL-4RL and T7AS·4RS translocation line WR41-1 $\times$ Shixin 633 and the powdery mildew reactions of WR41-1, Shixin 633, and their $\mathrm{F}_{2}$ plants tested at different growth stages using Mingxian 169 and Huixianhong as susceptible controls

\begin{tabular}{|c|c|c|c|c|c|c|c|}
\hline \multirow[b]{2}{*}{ Plant material } & \multirow[b]{2}{*}{ Plants $(n)$} & \multirow[b]{2}{*}{ GISH $^{\mathbf{a}}$} & \multicolumn{2}{|c|}{ Marker $^{\mathbf{b}}$} & \multicolumn{3}{|c|}{ Phenotype $^{c}$} \\
\hline & & & MAG1424 & KSUM62 & Seedling & Boot & Milk \\
\hline Mingxian 169 & 20 & No translocation & - & - & $\mathrm{S}$ & $\mathrm{S}$ & $\mathrm{S}$ \\
\hline Huixianhong & 20 & No translocation & - & - & S & S & S \\
\hline WR41-1 & 20 & 4RL disomic plus $4 \mathrm{RS}$ disomic translocation & + & + & $\mathrm{R}$ & $\mathrm{R}$ & $\mathrm{R}$ \\
\hline Shixin 633 & 20 & No translocation & - & - & $\mathrm{S}$ & $\mathrm{S}$ & $\mathrm{S}$ \\
\hline \multirow[t]{7}{*}{$F_{2}$ plants of WR $41 \times$ Shixin 633} & 3 & 4RS monosomic translocation & - & + & $S$ & $S$ & S \\
\hline & 12 & 4RL monosomic translocation & + & - & $\mathrm{R}$ & $\mathrm{R}$ & $\mathrm{R}$ \\
\hline & 3 & 4RL disomic translocation & + & - & $\mathrm{R}$ & $\mathrm{R}$ & $\mathrm{R}$ \\
\hline & 3 & $\begin{array}{l}\text { 4RL monosomic plus } 4 \mathrm{RS} \text { monosomic } \\
\text { translocation }\end{array}$ & + & + & $\mathrm{R}$ & $\mathrm{R}$ & $\mathrm{R}$ \\
\hline & 6 & $\begin{array}{l}\text { 4RL disomic plus } 4 \mathrm{RS} \text { monosomic } \\
\text { translocation }\end{array}$ & + & + & $\mathrm{R}$ & $\mathrm{R}$ & $\mathrm{R}$ \\
\hline & 3 & 4RL disomic plus 4RS disomic translocation & + & + & $\mathrm{R}$ & $\mathrm{R}$ & $\mathrm{R}$ \\
\hline & 30 & No translocation & - & - & $\mathrm{S}$ & $\mathrm{S}$ & $\mathrm{S}$ \\
\hline
\end{tabular}

a GISH = genomic in situ hybridization.

b Plus signs and minus signs denote the presence and absence, respectively, of the specific chromosome arm 4RL or 4RS.

${ }^{c}$ At the seedling stage, $\mathrm{R}=$ resistant (infection type [IT] 0 to 2 ) and $\mathrm{S}=$ susceptible (IT 3 to 4 ) (Si et al. 1992). At the adult stage, $\mathrm{R}=$ resistant (IT 0 to 4 ) and $\mathrm{S}=$ susceptible (IT 5 to 9) (Sheng and Duan 1991).

A
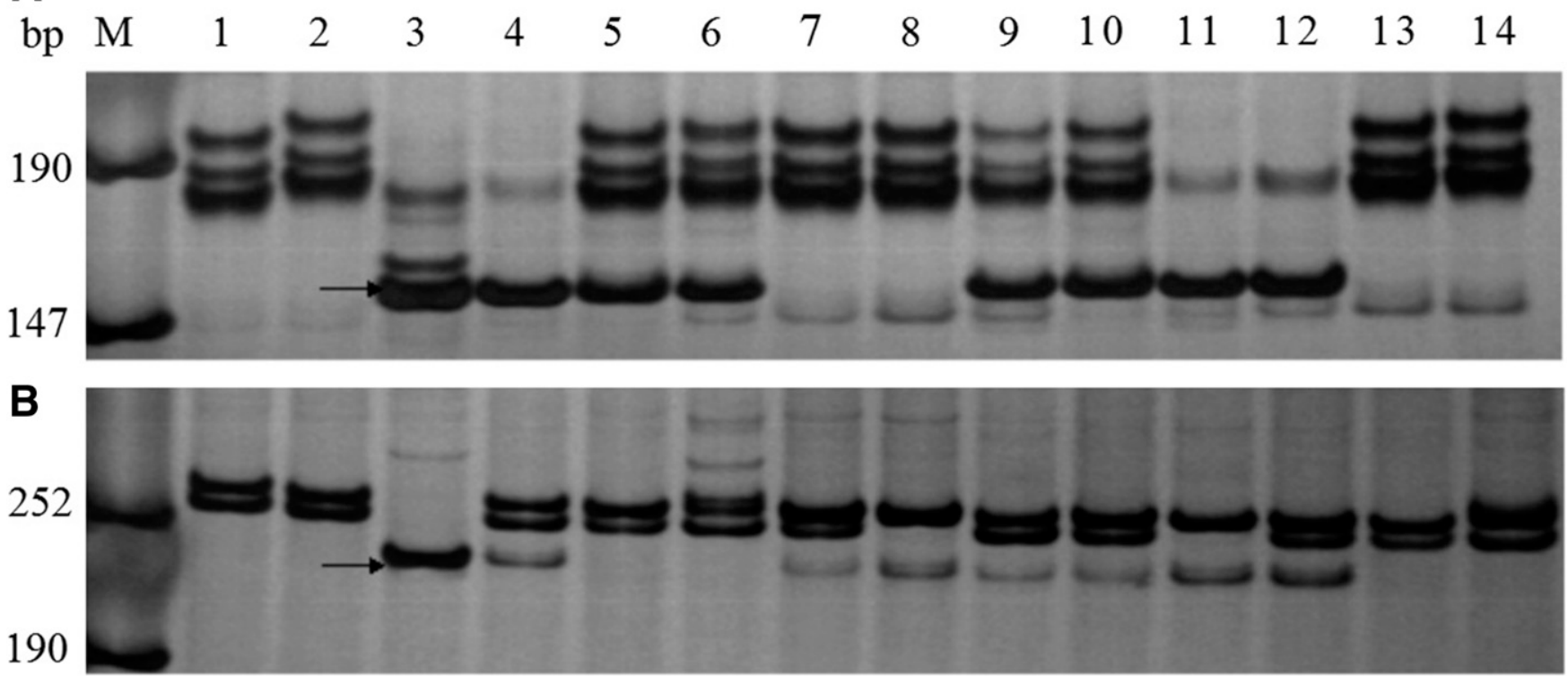

Fig. 2. Molecular marker detection of chromosome 4R translocations using expressed sequence tag simple sequence repeat markers A, KSUM62 and B, MAG1424 specific for chromosome 4RS and 4RL of rye in wheat-rye progenies, respectively. The 160-and 235-bp bands indicate the diagnostic DNA fragments specific for 4RS and 4RL, respectively. Lanes are as follows: $\mathrm{M}=$ marker pUC18/Mspl, $1=$ Chinese Spring, $2=$ Xiaoyan 6, $3=$ WR41-1, $4=4 \mathrm{RS}$ disomic plus 4RL disomic translocation, 5 and $6=4 \mathrm{RS}$ monosomic translocation, $7=4 \mathrm{RL}$ monosomic translocation, $8=4 \mathrm{RL}$ disomic translocation, 9 and $10=4 \mathrm{RS}$ monosomic plus $4 \mathrm{RL}$ monosomic translocation, 11 and $12=4 \mathrm{RS}$ monosomic plus $4 R L$ disomic translocation, and 13 to $14=$ no rye translocation. 
wheat cultivar Xiaoyan 6, which has high yield potential, good bread-making quality with molecular weight glutenin subunits, early maturity, and wide adaptation (Ma et al. 2018a). Meanwhile, the new translocations derived from WR41-1 were further introduced into the background of high-yield cultivar Shixin 633. However, both Xiaoyan 6 and Shixin 633 were highly susceptible to powdery mildew (Ma et al. 2018b). After chromosome arm 4RL was transferred into wheat cultivar Shixin 633, the new lines are highly resistant to powdery mildew.
When 4RL translocation materials with powdery mildew resistance are used in breeding, the 4RL-specific markers are very useful for accelerating the selection for chromosome arm 4RL. The two KASP markers of chromosome arm 4RL in particular were developed in this study and will greatly accelerate the utilization of chromosome arm 4RL in wheat improvement. In fact, chromosome arm 4RL has been transferred to different genetic backgrounds in our laboratory, including to several well-known Chinese cultivars such as Shixin 733, Shixin 828, Gao 8901, Jishi 02-1, and Jimai 22. In the

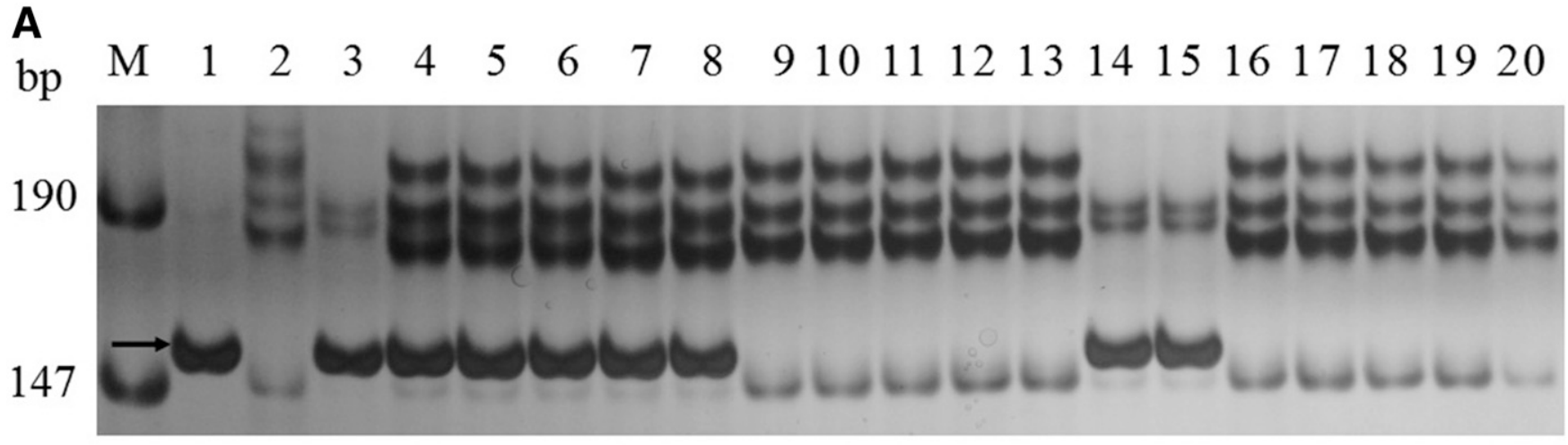

B

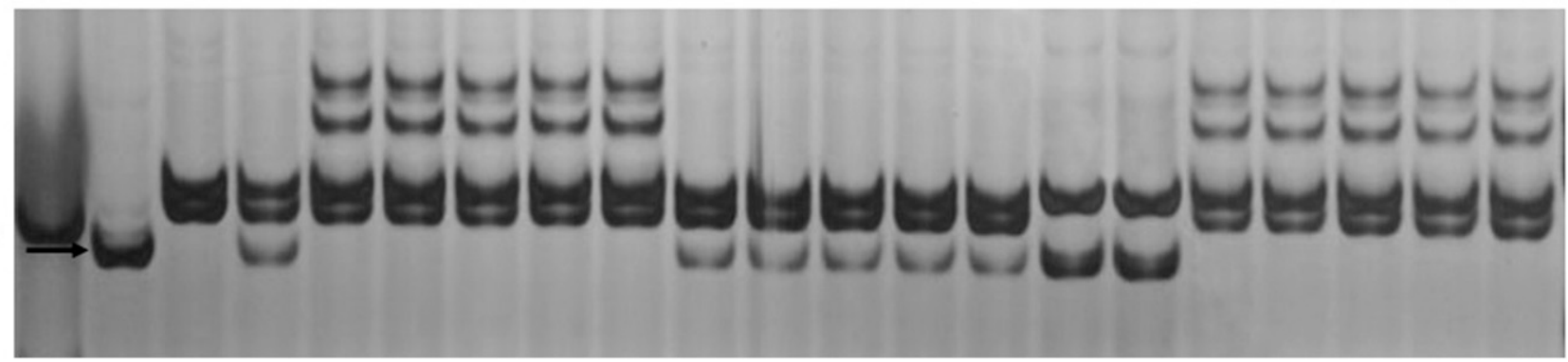

Fig. 3. Molecular marker detection of selected self-pollinated progenies of chromosome $4 \mathrm{R}$ translocations using expressed sequence tag simple sequence repeat markers $\mathrm{A}$, KSUM62 and B, MAG1424 specific for 4RS and 4RL of rye chromosome in wheat-rye progenies, respectively. Lanes are as follows: $M=$ marker pUC18/Mspl, $1=$ German White rye, 2 = Xiaoyan 6, 3 = WR41-1, 4 to 8 = selected chromosome 4R translocations with 4RS translocation from the self-pollinated progenies of 4RS monosomic translocation materials, 9 to $13=$ selected chromosome $4 R$ translocations with $4 R L$ translocation from self-pollinated progenies of $4 R L$ monosomic translocation materials, 14 and 15 = selected chromosome 4R translocations with 4RS and 4RL translocations from the self-pollinated progenies of 4RS monosomic plus 4RL monosomic translocation materials, and 16 to $20=$ self-pollinated progenies with no rye translocation.

Table 2. Marker detection and powdery mildew reactions of self-pollinated progenies of translocations and their parents WR41 and Shixin 633 tested at different growth stages

\begin{tabular}{|c|c|c|c|c|c|}
\hline \multirow[b]{2}{*}{ Plant material } & \multirow[b]{2}{*}{ Plants (n) } & \multirow[b]{2}{*}{ Plants tested $(n)$} & \multicolumn{3}{|c|}{ Reaction phenotype $^{a}$} \\
\hline & & & Seedling & Boot & Milk \\
\hline Mingxian 169 & 20 & 20 & $\mathrm{~S}$ & $\mathrm{~S}$ & $\mathrm{~S}$ \\
\hline Huixianhong & 20 & 20 & $\mathrm{~S}$ & $\mathrm{~S}$ & $\mathrm{~S}$ \\
\hline WR41-1 & 20 & 20 & $\mathrm{R}$ & $\mathrm{R}$ & $\mathrm{R}$ \\
\hline Shixin 633 & 20 & 20 & S & S & $\mathrm{S}$ \\
\hline 4RS monosomic translocation & 40 & 16 & S & S & $\mathrm{S}$ \\
\hline 4RL monosomic translocation & 155 & 8 & $\mathrm{R}$ & $\mathrm{R}$ & $\mathrm{R}$ \\
\hline \multirow[t]{3}{*}{ 4RL plus 4RS monosomic translocations } & 26 & 1 (4RS translocation) & S & $S$ & $\mathrm{~S}$ \\
\hline & & 1 (4RL translocation) & $\mathrm{R}$ & $\mathrm{R}$ & $\mathrm{R}$ \\
\hline & & 2 (4RS plus 4RL translocations) & $\mathrm{R}$ & $\mathrm{R}$ & $\mathrm{R}$ \\
\hline
\end{tabular}

a At the seedling stage, $\mathrm{R}=$ resistant (infection type [IT] 0 to 2 ) and $\mathrm{S}=$ susceptible (IT 3 to 4 ) (Si et al. 1992). At the adult stage, $\mathrm{R}=$ resistant (IT 0 to 4 ) and $\mathrm{S}=$ susceptible (IT 5 to 9) (Sheng and Duan 1991).

Table 3. Sequences of the two 4RL-specific codominant kompetitive allele-specific PCR (KASP) markers SWK4RL1 and SWK4RL2

\begin{tabular}{llll}
\hline Specific KASP marker & \multicolumn{1}{c}{ Forward primer $\mathbf{1}\left(\mathbf{5}^{\prime} \text { to } \mathbf{3}^{\prime}\right)^{\mathbf{a}}$} & \multicolumn{1}{c}{ Forward primer $\mathbf{2}\left(\mathbf{5}^{\prime} \text { to } \mathbf{3}^{\prime}\right)^{\mathbf{b}}$} & Common primer $\left(\mathbf{5}^{\prime}\right.$ to $\left.\mathbf{3}^{\prime}\right)$ \\
\hline SWK4RL1 & TCATCAGAATACAGCTAAGCG & TCATCAGAATACAGCTAAGCA & AGAAGTTGATGCGCATTGGG \\
SWK4RL2 & TTCTGAAGGTGCTCAGC & TTCTGAAGGTGCTCAGT & TCACTTGATGCACTGGC \\
\hline
\end{tabular}

\footnotetext{
a Forward primer 1 was labeled with FAM: GAAGGTGACCAAGTTCATGCT.
}

b Forward primer 2 was labeled with HEX: GAAGGTCGGAGTCAACGGAT. 
future, ${ }^{60} \mathrm{Co} \gamma$ radiation and $p h 1 b$-induced homeologous recombination will be used to develop translocation lines with smaller segments of rye chromatin carrying powdery mildew resistance.

As more lines with alien segments are introduced into wheat, the development and application of species-specific molecular markers, particularly those that can trace the target traits simultaneously, are preferred by researchers and breeders to select the most desirable progenies in a more efficient way. For instance, molecular marker $M B H 1$ has been efficiently used in marker-assisted selection (MAS) to select and distinguish translocation chromosomes carrying
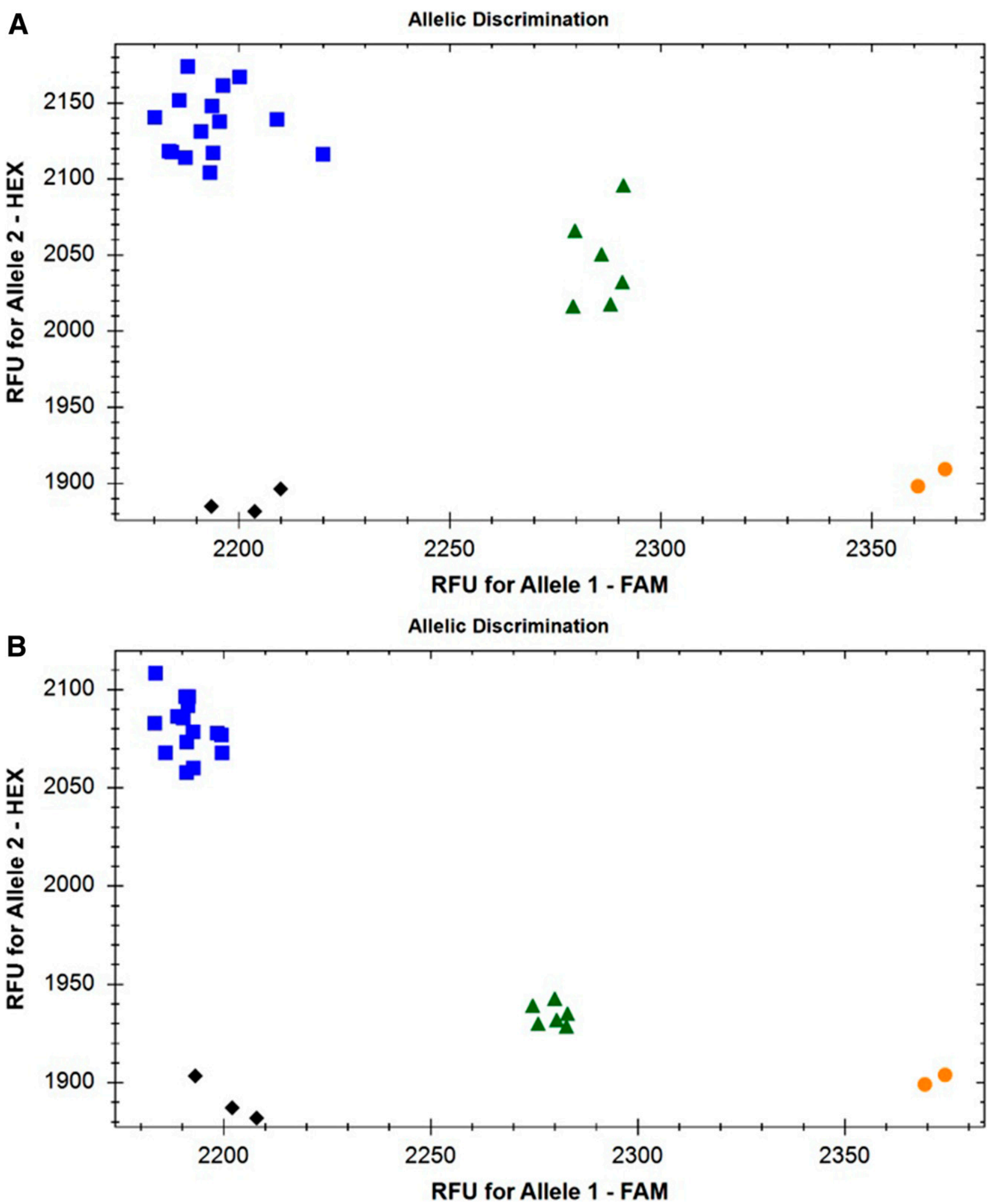

Fig. 4. Validation and genotyping results of the two 4RL-specific codominant kompetitive allele-specific PCR markers A, SWK4RL1 and B, SWK4RL2. Two orange rotundity shapes indicate rye samples with homozygous Allele1/Allele1 genotype: German White and Imperial. Fifteen blue square shapes indicate wheat samples and samples of wheat-rye introgression without chromosome arm 4RL with homozygous Allele2/Allele2 genotype: Chinese Spring, Xiaoyan 6, wheat-rye $1 R$ to $3 R$ and $5 R$ to $7 R$ disomic addition lines, 4RS ditelosomic addition line of Chinese Spring-Imperial, three 4RS monosomic translocations characterized by genomic in situ hybridization (GISH), and three of the selfpollinated progenies with no rye translocation. Six green triangle shapes indicate wheat-rye 4RL introgression samples with heterozygous Allele1/Allele2 genotype: wheat-rye 4R disomic addition line and 4RL ditelosomic addition line of Chinese Spring-Imperial, WR41-1, and three 4RL monosomic translocations characterized by GISH. Three black diamond shapes indicate the no-template control. RFU = relative fluorescence unit, HEX = 5-hexachloro-fluorescein, FAM = 6-carboxy-fluorescein. 
Pm21 and PmV from Haynaldia villosa (Bie et al. 2015). Despite numerous studies on developing molecular markers to tag target genes, most of the markers have not performed as well as expected in breeding for the following reasons: low resolution, adverse genetic backgrounds, or environmental effects (Bie et al. 2015). Compared with conventional markers, a high-throughput SNP-based genotyping technology such as KASP markers has the advantages of high resolution, high efficiency, good genetic stability, and low cost, which enable the detailed genotypic characterization of individual plants and greatly improve the process of genomic selection in wheat breeding programs (Ma et al. 2018a, b; Qureshi et al. 2018; Semagn et al. 2014; Thomson 2014; Zhao et al. 2014). Unlike the abundance of published sequencing data for wheat, many relatives of wheat lack high-quality whole-genome sequencing information. Benefiting from the advent of next-generation sequencing technology, KASP markers could also be successfully developed and applied to the detection of alien segments, providing strong support for accelerating the tracking of alien fragments in wheat. By combining chromosome flow sorting and next-generation sequencing technology, Tiwari et al. (2014) developed KASP markers that could detect 5 $\mathrm{M}^{\mathrm{g}}$ segments conferring resistance in a wheat-Aegilops geniculate introgression line. Based on the RNA-seq data, Ma et al. (2018b) developed codominant KASP markers that were able to detect Agropyron cristatum chromosome. Rahmatov et al. (2016) developed three dominant rye $2 \mathrm{RL}$-specific KASP markers from the iSelect SNP markers, which could successfully detect the resistant parent allele in derived families, although there were no polymorphisms for the SSR or PLUG markers.

With the exception of these studies, few alien chromosomespecific KASP markers have been reported up to now. In this study, based on the efficient SLAF-seq next-generation sequencing method, two codominant KASP markers specific for chromosome arm 4RL (SWK4RL1 and SWK4RL2) were developed and will be used for MAS of progenies carrying chromosome $4 \mathrm{R}$ or $4 \mathrm{RL}$ with the powdery mildew resistance gene derived from WR41-1 crossed with the wheat susceptible cultivars. They will greatly improve the efficiency of identification of chromosome arm 4RL in large populations and several novel materials were identified and selected for further breeding. Therefore, the 4RL-specific codominant KASP markers could be used as a powerful tool to facilitate MAS for chromosome $4 \mathrm{R}$ or $4 \mathrm{RL}$ with powdery mildew resistance in wheat breeding programs.

\section{Acknowledgments}

The following researchers provided valuable plant materials for this study: the set of wheat-rye ditelosomic addition lines of Holdfast-King II was kindly supplied by Dr. Adrian Turner (John Innes Centre, Norwich, UK); wheat cultivar Holdfast and the set of wheat-rye disomic addition lines of Holdfast-King II were kindly supplied by Professor Zongxiang Tang (Sichuan Agricultural University, Chengdu, China); rye cultivar King II was kindly contributed by Dr. Yiwen Li (Institute of Genetics and Developmental Biology, Chinese Academy of Sciences, Beijing, China); and the set of wheat-rye disomic lines, 4RS ditelosomic addition line, and 4RL ditelosomic addition line of CS-Imperial were kindly provided by Dr. John Raupp (Kansas State University, Manhattan, KS).

\section{Literature Cited}

An, D. G., Li, L. H., Li, J. M., Li, H. J., and Zhu, Y. G. 2006. Introgression of resistance to powdery mildew conferred by chromosome $2 \mathrm{R}$ by crossing wheat nullisomic 2D with rye. J. Integr. Plant Biol. 48:838-847.

An, D. G., Ma, P. T., Zheng, Q., Fu, S. L., Li, L. H., Han, F. P., Han, G. H., Wang, J., Xu, Y. F., Jin, Y. L., Luo, Q. L., and Zhang, X. T. 2019. Development and molecular cytogenetic identification of a new wheat-rye 4R chromosome disomic addition line with resistances to powdery mildew, stripe rust and sharp eyespot. Theor. Appl. Genet. 132:257-272.

An, D. G., Zheng, Q., Luo, Q. L., Ma, P. T., Zhang, H. X., Li, L. H., Han, F. P., Xu, H. X., Xu, Y. F., and Zhang, X. T. 2015. Molecular cytogenetic identification of a new wheat-rye $6 \mathrm{R}$ chromosome disomic addition line with powdery mildew resistance. PLoS One 10:e134534.

An, D. G., Zheng, Q., Zhou, Y. L., Ma, P. T., Lv, Z. L., Li, L. H., Li, B., Luo, Q. L., $\mathrm{Xu}, \mathrm{H}$. X., and Xu, Y. F. 2013. Molecular cytogenetic characterization of a new wheat-rye $4 \mathrm{R}$ chromosome translocation line resistant to powdery mildew. Chromosome Res. 21:419-432.

Bie, T. D., Zhao, R. H., Zhu, S. Y., Chen, S. L., Chen, B., Zhang, B. Q., Gao, D. R., Jiang, Z. N., Chen, T. T., Wang, L., Wu, R. L., and He, H. G. 2015.
Development and characterization of marker $M B H 1$, simultaneously tagging genes $P m 21$ and $P m V$, conferring resistance to powdery mildew in wheat. Mol. Breed. 35:189.

Chebotar, S., Röder, M. S., Korzun, V., Saal, B., Weber, W. E., and Börner, A. 2003. Molecular studies on genetic integrity of open-pollinating species rye (Secale cereale L.) after long-term genebank maintenance. Theor. Appl. Genet. 107:1469-1476.

Chen, P. D., Liu, W. X., Yuan, J. H., Wang, X. E., Zhou, B., Wang, S. L., Zhang, S. Z., Feng, Y. G., Yang, B. J., Liu, G. X., Liu, D. J., Qi, L. L., Zhang, P., Friebe, B., and Gill, B. S. 2005. Development and characterization of wheat-Leymus racemosus translocation lines with resistance to Fusarium head blight. Theor. Appl. Genet. 111:941-948.

Chen, P. D., You, C. F., Hu, Y., Chen, S. W., Zhou, B., Cao, A. Z., and Wang, X. E. 2013. Radiation-induced translocations with reduced Haynaldia villosa chromatin at the Pm21 locus for powdery mildew resistance in wheat. Mol. Breed. 31:477-484.

Chikmawati, T., Miftahudin, M., Skovmand, B., and Gustafson, J. P. 2012. Amplified fragment length polymorphism-based genetic diversity among cultivated and weedy rye (Secale cereale L.) accessions. Genet. Resour. Crop Evol. 59:1743-1752.

Cowger, C., Mehra, L., Arellano, C., Meyers, E., and Murphy, J. P. 2018 Virulence differences in Blumeria graminis $\mathrm{f}$. sp. tritici from the central and eastern United States. Phytopathology 108:402-411.

Danilova, T. V., Friebe, B., Gill, B. S., Poland, J., and Jackson, E. 2018 Development of a complete set of wheat-barley group-7 Robertsonian translocation chromosomes conferring an increased content of $\beta$-glucan. Theor. Appl. Genet. 131:377-388.

Danilova, T. V., Zhang, G. R., Liu, W. X., Friebe, B., and Gill, B. S. 2017. Homoeologous recombination-based transfer and molecular cytogenetic mapping of a wheat streak mosaic virus and Triticum mosaic virus resistance gene Wsm3 from Thinopyrum intermedium to wheat. Theor. Appl. Genet. 130:549-556.

Dhakal, S., Tan, C. T., Anderson, V., Yu, H. J., Fuentealba, M. P., Rudd, J. C. Haley, S. D., Xue, Q. W., Ibrahim, A. M. H., Garza, L., Devkota, R. N., and Liu, S. Y. 2018. Mapping and KASP marker development for wheat curl mite resistance in 'TAM 112' wheat using linkage and association analysis. Mol. Breed. 38:119.

Edet, O. U., Kim, J. S., Okamoto, M., Hanada, K., Takeda, T., Kishii, M., Gorafi, Y. S. A., and Tsujimoto, H. 2018. Efficient anchoring of alien chromosome segments introgressed into bread wheat by new Leymus racemosus genomebased markers. BMC Genet. 19:18.

Endo, T. R. 2007. The gametocidal chromosome as a tool for chromosome manipulation in wheat. Chromosome Res. 15:67-75.

Falke, K. C., Sušić, Z., Wilde, P., Wortmann, H., Möhring, J., Piepho, H. P., Geiger, H. H., and Miedaner, T. 2009. Testcross performance of rye introgression lines developed by marker-assisted backcrossing using an Iranian accession as donor. Theor. Appl. Genet. 118:1225-1238.

Friebe, B., Heun, M., Tuleen, N., Zeller, F. J., and Gill, B. S. 1994. Cytogenetically monitored transfer of powdery mildew resistance from rye into wheat. Crop Sci. 34:621-625.

Friebe, B., Jiang, J., Raupp, W. J., McIntosh, R. A., and Gill, B. S. 1996 Characterization of wheat-alien translocations conferring resistance to diseases and pests: Current status. Euphytica 91:59-87.

Fu, S. L., Ren, Z. L., Chen, X. M., Yan, B. J., Tan, F. Q., Fu, T. H., and Tang, Z. X 2014. New wheat-rye 5DS-4RS-4RL and 4RS-5DS-5DL translocation lines with powdery mildew resistance. J. Plant Res. 127:743-753.

Guo, X., Shi, Q. H., Wang, J., Hou, Y. L., Wang, Y. H., and Han, F. P. 2015 Characterization and genome changes of new amphiploids from wheat wide hybridization. J. Genet. Genomics 42:459-461.

Han, F., Gao, Z., and Birchler, J. A. 2009. Reactivation of an inactive centromere reveals epigenetic and structural components for centromere specification in maize. Plant Cell 21:1929-1939.

Han, F. P., Lamb, J. C., and Birchler, J. A. 2006. High frequency of centromere inactivation resulting in stable dicentric chromosomes of maize. Proc. Natl Acad. Sci. USA 103:3238-3243.

Hao, M., Liu, M., Luo, J. T., Fan, C. L., Yi, Y. J., Zhang, L. Q., Yuan, Z. W., Ning, S. Z., Zheng, Y. L., and Liu, D. C. 2018. Introgression of powdery mildew resistance gene $P m 56$ on rye chromosome arm $6 \mathrm{RS}$ into wheat. Front. Plant Sci. 9:1040.

He, H. G., Ji, Y. Y., Zhu, S. Y., Li, B., Zhao, R. H., Jiang, Z. N., and Bie, T. D. 2017. Genetic, physical and comparative mapping of the powdery mildew resistance gene Pm 21 originating from Dasypyrum villosum. Front. Plant Sci. $8: 1914$.

Hechanova, S. L., Prusty, M. R., Kim, S. R., Ballesfin, L., Ramos, J., Prahalada, G. D. and Jena, K. K. 2018. Monosomic alien addition lines (MAALs) of Oryza rhizomatis in Oryza sativa: Production, cytology, alien trait introgression, molecular analysis and breeding application. Theor. Appl. Genet. 131:2197-2211.

Heun, M., Friebe, B., and Bushuk, W. 1990. Chromosomal location of the powdery mildew resistance gene of Amigo wheat. Phytopathology 80: $1129-1133$

Hsam, S. L. K., and Zeller, F. J. 1997. Evidence of allelism between genes Pm8 and Pm17 and chromosomal location of powdery mildew and leaf rust resistance genes in the common wheat cultivar 'Amigo'. Plant Breed. 116:119-122. 
Huang, X. Q., and Röder, M. S. 2004. Molecular mapping of powdery mildew resistance genes in wheat: A review. Euphytica 137:203-223.

Li, F., Li, Y. H., Cao, L. R., Liu, P. Y., Geng, M. M., Zhang, Q., Qiu, L., Sun, Q. X., and Xie, C. J. 2018. Simultaneous transfer of leaf rust and powdery mildew resistance genes from hexaploid triticale cultivar Sorento into bread wheat. Front. Plant Sci. 9:85.

Li, G. Q., Cowger, C., Wang, X. W., Carver, B. F., and Xu, X. Y. 2019. Characterization of Pm65, a new powdery mildew resistance gene on chromosome 2AL of a facultative wheat cultivar. Published ahead of print. Theor. Appl. Genet. 10.1007/s00122-019-03377-2.

Liu, L. Q., Luo, Q. L., Li, H. W., Li, B., Li, Z. S., and Zheng, Q. 2018. Physical mapping of the blue-grained gene from Thinopyrum ponticum chromosome $4 \mathrm{Ag}$ and development of blue-grain-related molecular markers and a FISH probe based on SLAF-seq technology. Theor. Appl. Genet. 131:2359-2370.

Liu, W. X., Koo, D. H., Xia, Q., Li, C. X., Bai, F. Q., Song, Y. L., Friebe, B., and Gill, B. S. 2017. Homoeologous recombination-based transfer and molecular cytogenetic mapping of powdery mildew-resistant gene Pm57 from Aegilops searsii into wheat. Theor. Appl. Genet. 130:841-848.

Ma, F. F., Xu, Y. F., Ma, Z. Q., Li, L. H., and An, D. G. 2018a. Genome-wide association and validation of key loci for yield-related traits in wheat founder parent Xiaoyan 6. Mol. Breed. 38:91.

Ma, P. T., Xu, H. X., Xu, Y. F., Li, L. H., Qie, Y. M., Luo, Q. L., Zhang, X. T., Li, X. Q., Zhou, Y. L., and An, D. G. 2015. Molecular mapping of a new powdery mildew resistance gene $P m 2 b$ in Chinese breeding line KM2939. Theor. Appl. Genet. 128:613-622.

Ma, P. T., Xu, H. X., Xu, Y. F., Song, L. P., Liang, S. S., Sheng, Y., Han, G. H., Zhang, X. T., and An, D. G. 2018b. Characterization of a powdery mildew resistance gene in wheat breeding line $10 \mathrm{~V}-2$ and its application in markerassisted selection. Plant Dis. 102:925-931.

Martinez, I., Bernard, M., Nicolas, P., and Bernard, S. 1994. Study of androgenetic performance and molecular characterisation of a set of wheat-rye addition lines. Theor. Appl. Genet. 89:982-990.

McIntosh, R. A., Dubcovsky, J., Rogers, W. J., Morris, C., and Xia, X. C. 2017. Catalogue of gene symbols for wheat: 2017 supplement. http:// shigen.nig.ac.jp/wheat/komugi/genes/symbolClassList.jsp

Morgounov, A., Tufan, H. A., Sharma, R., Akin, B., Bagci, A., Braun, H. J., Kaya, Y., Keser, M., Payne, T. S., Sonder, K., and McIntosh, R. A. 2012. Global incidence of wheat rusts and powdery mildew during 1969-2010 and durability of resistance of winter wheat variety Bezostaya 1. Eur. J. Plant Pathol. 132:323-340.

Parks, R., Carbone, I., Murphy, J. P., Marshall, D., and Cowger, C. 2008. Virulence structure of the eastern U.S. wheat powdery mildew population. Plant Dis. 92:1074-1082.

Qi, W. L., Tang, Y., Zhu, W., Li, D. Y., Diao, C. D., Xu, L. L., Zeng, J., Wang, Y., Fan, X., Sha, L. N., Zhang, H. Q., Zheng, Y. L., Zhou, Y. H., and Kang, H. Y. 2016. Molecular cytogenetic characterization of a new wheat-rye 1BL•1RS translocation line expressing superior stripe rust resistance and enhanced grain yield. Planta 244:405-416.

Qureshi, N., Kandiah, P., Gessese, M. K., Nsabiyera, V., Wells, V., Babu, P., Wong, D., Hayden, M., Bariana, H., and Bansal, U. 2018. Development of co-dominant KASP markers co-segregating with Ug99 effective stem rust resistance gene $S r 26$ in wheat. Mol. Breed. 38:97.

Rahmatov, M., Rouse, M. N., Nirmala, J., Danilova, T., Friebe, B., Steffenson, B. J., and Johansson, E. 2016. A new 2DS·2RL Robertsonian translocation transfers stem rust resistance gene Sr59 into wheat. Theor. Appl. Genet. 129:1383-1392.

Ren, T. H., Ren, Z. L., Yang, M. Y., Yan, B. J., Tan, F. Q., Fu, S. L., Tang, Z. X., and $\mathrm{Li}, \mathrm{Z}$. 2018. Novel source of $1 \mathrm{RS}$ from Baili rye conferred high resistance to diseases and enhanced yield traits to common wheat. Mol. Breed. 38:101.

Rogowsky, P. M., Liu, J. Y., Manning, S., Taylor, C., and Langridge, P. 1992. Structural heterogeneity in the R173 family of rye-specific repetitive DNA sequences. Plant Mol. Biol. 20:95-102.

Selter L. L., Shatalina, M., Singla, J., and Keller, B. 2013. Identification and implementation of resistance: Genomics-assisted use of genetic resources for breeding against powdery mildew and Stagonospora nodorum blotch in wheat. Pages 359-383 in Genomics of Plant Genetic Resources. R. Tuberosa, A. Graner, and E. Frison, eds. Springer, Dordrecht, Netherlands.

Semagn, K., Babu, R., Hearne, S., and Olsen, M. 2014. Single nucleotide polymorphism genotyping using kompetitive allele specific PCR (KASP):
Overview of the technology and its application in crop improvement. Mol Breed. 33:1-14

Sharp, P. J., Kreis, M., Shewry, P. R., and Gale, M. D. 1988. Location of $\beta$-amylase sequences in wheat and its relatives. Theor. Appl. Genet. 75: 286-290.

Sheng, B. Q., and Duan, X. Y. 1991. Improvement of scale 0-9 method for scoring adult plant resistance to powdery mildew of wheat. Beijing Agr. Sci. 1:38-39.

Si, Q. M., Zhang, X. X., Duan, X. Y., Sheng, B. Q., and Zhou, Y. L. 1992. On gene analysis and classification of powdery mildew (Erysiphe graminis f. sp. tritici) resistant wheat varieties. Acta Phytopathol. Sin. 22:349-355.

Tang, X. Q., Shi, D., Xu, J., Li, Y. L., Li, W. J., Ren, Z. L., and Fu, S. L. 2014 Molecular cytogenetic characteristics of a translocation line between common wheat and Thinopyrum intermedium with resistance to powdery mildew. Euphytica 197:201-210.

Targońska, M., Bolibok-Brągoszewska, H., and Rakoczy-Trojanowska, M. 2016. Assessment of genetic diversity in Secale cereale based on SSR markers. Plant Mol. Biol. Report. 34:37-51.

Thomson, M. J. 2014. High-throughput SNP genotyping to accelerate crop improvement. Plant Breed. Biotechnol. 2:195-212.

Tiwari, V. K., Wang, S. C., Sehgal, S., Vrána, J., Friebe, B., Kubaláková, M., Chhuneja, P., Doležel, J., Akhunov, E., Kalia, B., Sabir, J., and Gill, B. S. 2014. SNP discovery for mapping alien introgressions in wheat. BMC Genomics 15:273.

Wang, C. M., Zheng, Q., Li, L. H., Niu, Y. C., Wang, H. B., Li, B., Zhang, X. T., Xu, Y. F., and An, D. G. 2009. Molecular cytogenetic characterization of a new T2BL-1RS wheat-rye chromosome translocation line resistant to stripe rust and powdery mildew. Plant Dis. 93:124-129.

Xu, H. X., Yin, D. D., Li, L. H., Wang, Q. X., Li, X. Q., Yang, X. M., Liu, W. H., and An, D. G. 2012. Development and application of EST-based markers specific for chromosome arms of rye (Secale cereale L.). Cytogenet. Genome Res. 136:220-228.

Yu, S. Y., Long, H., Yang, H., Zhang, J., Deng, G. B., Pan, Z. F., Zhang, E. L., and Yu, M. Q. 2012. Molecular detection of rye (Secale cereale L.) chromatin in wheat line 07jian126 (Triticum aestivum L.) and its association to wheat powdery mildew resistance. Euphytica 186:247-255.

Zadoks, J. C., Chang, T. T., and Konzak, C. F. 1974. A decimal code for the growth stages of cereals. Weed Res. 14:415-421.

Zeller, F. J., and Hsam, S. L. K. 1996. Chromosomal location of a gene suppressing powdery mildew resistance genes $\mathrm{Pm} 8$ and $\mathrm{Pm} 17$ in common wheat (Triticum aestivum L. em. Thell.). Theor. Appl. Genet. 93:38-40.

Zeller, F. J., and Koller, O. L. 1981. Identification of a 4A/7R and a 7B/4R wheatrye chromosome translocation. Theor. Appl. Genet. 59:33-37.

Zhang, J. P., Zhang, P., Hewitt, T., Li, J. B., Dundas, L., Schnippenkoetter, W., Hoxha, S., Chen, C. H., Park, R., and Lagudah, E. 2019. A strategy for identifying markers linked with stem rust resistance in wheat harbouring an alien chromosome introgression from a non-sequenced genome. Theor. Appl. Genet. 132:125-135.

Zhang, Q. P., Li, Q., Wang, X. E., Wang, H. Y., Lang, S. P., Wang, Y. N., Wang, S. L., Chen, P. D., and Liu, D. J. 2005. Development and characterization of a Triticum aestivum-Haynaldia villosa translocation line T4VS-4DL conferring resistance to wheat spindle streak mosaic virus. Euphytica 145:317-320.

Zhang, R. Q., Fan, Y. L., Kong, Z. X., Wang, Z. J., Wu, J. Z., Xing, L. P., Cao, A. Z., and Feng, Y. G. 2018. Pm62, an adult-plant powdery mildew resistance gene introgressed from Dasypyrum villosum chromosome arm 2VL into wheat. Theor. Appl. Genet. 131:2613-2620.

Zhang, R. Q., Sun, B. X., Chen, J., Cao, A. Z., Xing, L. P., Feng, Y. G., Lan, C. X. and Chen, P. D. 2016. Pm55, a developmental-stage and tissue-specific powdery mildew resistance gene introgressed from Dasypyrum villosum into common wheat. Theor. Appl. Genet. 129:1975-1984.

Zhao, Y., Mette, M. F., Gowda, M., Longin, C. F., and Reif, J. C. 2014. Bridging the gap between marker-assisted and genomic selection of heading time and plant height in hybrid wheat. Heredity 112:638-645.

Zhong, G. C., Mu, S. M., and Zhang, Z. B. 2002. Wheat Distant Hybridization. Chinese Science Press, Beijing, China.

Zhuang, L. F., Sun, L., Li, A. X., Chen, T. T., and Qi, Z. J. 2011. Identification and development of diagnostic markers for a powdery mildew resistance gene on chromosome 2R of Chinese rye cultivar Jingzhouheimai. Mol. Breed. 27: 455-465. 